\title{
Optimal Allocation of UPFC to Minimize Real Power Losses using Firefly Algorithm
}

\author{
N. Kalpana, M. Venu Gopala Rao
}

\begin{abstract}
Reducing the loss of real power and maintaining the system voltage under limits are challenging and major problems in a power system network. Thus, it is desired to adapt an effective method that could clear up these problems or reduce it to the minimal level. Controllers with FACTS, for instance Unified Power Flow Controller (UPFC) can effectively enhance the various power system parameters. This paper proposes a new meta-heuristic algorithm known as firefly algorithm (FA) which is used to select the optimal location and sizing of UPFC, which minimizes the total real power losses and to maintain the voltage under limits, there by maintaining the power system stability. On the IEEE 14 bus system the performance of the proposed method is examined by taking into account the 125\%, 150\%, $175 \%$ and $200 \%$ overloading cases.
\end{abstract}

Keywords: Power flow algorithms, FFA, Power system stability, Optimal Location, UPFC.

\section{INTRODUCTION}

Day by day the satisfactory operation of contemporary power system is an essential need to fulfill the consumer desires. The need of electrical power is growing each day because of new upcoming industries and lavish in human way of life. In order to develop the power systems with developing the load both new transmission lines and generating stations want to be hooked up or the process of current infrastructure need to be extended to its limits. Diminished voltage profile (VP), and increased failure of transmission lines, [1-3] over-burdens are the significant difficulties for the establishments of new generating stations and transmissions lines. Rise in the demand for load and the decrease in resource generation create a new kind of challenge. This study relies to develop a method for enhancing the voltage, minimizing the losses and as a result remove voltage instability in a system. However Flexible AC Transmission System (FACTS) devices are an alternative answer to tackle few of these issues. Classifying the FACTS systems into three groups, 1 . Series controllers 2 . shunt

Revised Manuscript Received on February 19, 2020.

* Correspondence Author

N. Kalpana, Department of Electrical \&Electronics Engineering, Matrusri Engineering College, Osmaniya University, Hyderabad, Telangana, India.

M. Venu Gopala Rao, Professor \& HOD, Electrical and Electronics Engineering, PVP Siddartha Institute of Technology, Vijayawada, Andhra Pradesh, India. E-mail:venumannam@gmail.com

(C) The Authors. Published by Blue Eyes Intelligence Engineering and Sciences Publication (BEIESP). This is an open access article under the CC BY-NC-ND license (http://creativecommons.org/licenses/by-nc-nd/4.0/) controllers 3. Combined series-shunt controllers. In practice, Series Controllers and Shunt Controllers insert voltage and c urrent in a line [3]. The combined series-shunt controllers inject current into the device with the controller shunt part, a nd series voltage in line with the controller series part. Among various kinds of FACTS controllers, Unified Power Flow Controller (UPFC) [5-6] appears to be more practical in voltage balance enhancement [7-8] due to its potential to govern series and shunt variables concurrently.

The new control scheme based on the Firefly Algorithm was introduced in conjunction with this for better multiobj-e ctive optimization. FA is similar to other algorithms for optimization that use swarm intelligence such as PSO. But in many instances, this algorithm has superior performance.

The algorithm is focused upon the fireflies ' flashing activity that is present in nature. The control factors, for instance, UPFC location and tap position of the transformer and its factors become upgraded by the FA to enhance the primary function of RPL reduction, maintaining all of the factors inside the boundaries. The primary strategy will be to reduce the Real Power Los ses (RPL) and to boost the performance of Bus Voltages in order to achieve greater stability. To this, the L-index [9 ] is used to trace the network's heavy loss bus, to position the UPFC system and in addition to examine Voltage Stability. In this context the firefly algorithm is used to find the UPFC rating. The algorithm is used to assign UPFC device in IEEE14 bus to reduce the overall voltage deviation and loss of transmission and this is simulated with MAT laboratory Software. This paper is compressed among six parts, beginning with an introduction, followed by Section 2 the problem Formulation which includes the description of objective functions and problem constraints. The UPFC modeling is proposed in Section 3. Section 4 presents the FF algorithm implementation. It presents some interesting results along with a detailed discussion in Section 6. Finally, it summa- rizes the conclusions in Section 7.

\section{PROBLEM FORMULATION}

The principal aim is to restrict the loss of real power (RPL) to boost the line's Bus Voltages. To accomplish this, we need to find the UPFC's optimum rating that is subject to constraints of equality and inequality. That is expressed in mathematical terms as

Minimize X=[X1, X2, X3]

$$
\begin{aligned}
& \text { CC } X 1=\sum_{k \in N i} g_{k}\left(V_{i}^{2}=V_{j}^{2}-2 V_{i} V_{j} \cos \theta_{i j}\right)=P \text { activeloss } \\
& \text { (2) } \\
& \begin{array}{l}
\text { Published By: } \\
\text { Blue Eyes Intelligence Engineering } \\
\text { \& Sciences Publication }
\end{array}
\end{aligned}
$$


Total voltage profile of 1 per unit load buses from the initi-a l value by $\mathrm{C} 2$

$$
X 2=V D=\sum_{k=1}^{N}{ }^{P Q}\left(V_{K}-\text { Vrefk }\right)^{2}
$$

$\mathrm{X} 3$ gives the L-index for kth bus[12 ]:

$$
X 3=L_{k}=\left|1 \pm \frac{V_{o k}}{V_{k}}\right|=\frac{S_{k}^{*}}{Y_{k k} V_{k}^{2}}
$$

The problem of minimization concerns the resulting limits o n equality and inequality:

Equality constraints:

i) Constraints on load flow:

$P_{k}-V_{k} \sum_{j=1}^{N g} V_{j}\left(G_{k j} \cos \theta_{k j}+B_{k j} \sin \theta_{k j}\right)=0$,

$\mathrm{k}=1,2, \ldots . \mathrm{N}_{\mathrm{B}}-1$

$Q_{k}-V_{k} \sum V_{j}\left(\left(G_{k j} \cos \theta_{k j}-B_{k j} \sin \theta_{k j}\right)=0\right.$

$\mathrm{k}=1,2, \ldots . \mathrm{N}_{\mathrm{PQ}}-1$

Inequality constraints:

(ii) Voltage constraints:

$V_{i}^{\text {min }} \leq V_{i} \leq V_{i}^{\max }, i \in N_{B}$

(7)

(iii) Generation of Reactive Power (RPG) Limit:

$Q_{g i}{ }^{\min } \leq Q_{g i} \leq Q_{g i}^{\max }, i \in N_{g}$

(iv) Reactive Power (RP) Generation at capacitor banks:

$Q_{c i}{ }^{\min } \leq Q_{c i} \leq Q_{c i}^{\max }, i \in N_{c}$

(9)

(v) Transformer Tap Setting Limits are:

$t_{p}^{\min } \leq t_{p} \leq t_{p}^{\max }, p \in N_{t}$

(vi) Limit of power flow on transmission line:

$S_{i} \leq S_{i}{ }^{\max }, i \in N_{t}$

\section{UNIFIED POWER FLOW CONTROLLER}

In 1991 Gyugyi proposed the concept of UPFC [6 ]. Fig. 1 gives the fundamental representation of UPFC. The UPFC is incorporated by two switching converters, which shares the single dc link provided by dc storage capacitor. It utilizes two transformers in that one is associated in parallel and other is in series to connect the converter $1 \& 2$ in the transmission network. The converter which is associated to the line in series plays the primary function of the UPFC. It regulates the line active and reactive power by injecting the necessary voltage and phase angle into the line.[7]

The real power required for the converter 2 is delivered by the converter1 through a DC link, which is associated in parallel with the line. Additionally, it swaps the reactive power with the line thereby imparting effective control of reactive shunt compensation. In a transmission line the two converters control entire parameters. For example, active, reactive power, voltage regulation and phase angle control.

Figure 3 gives UPFC Mathematical Modeling. By UPFC' $\mathrm{s}$ mathematical modeling, the series converter gives the equa tions of injected real and reactive power as

$\mathrm{S}_{\text {series }}=\mathrm{P}_{\text {series }}+\mathrm{jQ} \mathrm{Q}_{\text {series }}$

Where
$P_{\text {series }}=r b_{x} V_{m} V_{n} \sin (\theta m-\theta n+\gamma)-r b_{x} V^{2} \sin \gamma$

$\mathrm{Q}_{\text {series }}=-\mathrm{rb}_{\mathrm{x}} \mathrm{V}_{\mathrm{m}} \mathrm{V}_{\mathrm{n}} \cos (\theta \mathrm{m}-\theta \mathrm{n}+\gamma)+\mathrm{rb}_{\mathrm{x}} \mathrm{V}^{2}{ }_{\mathrm{m}} \cos \gamma+$ $\mathrm{r}^{2} \mathrm{~b}_{\mathrm{x}} \mathrm{V}_{\mathrm{m}}^{2}$

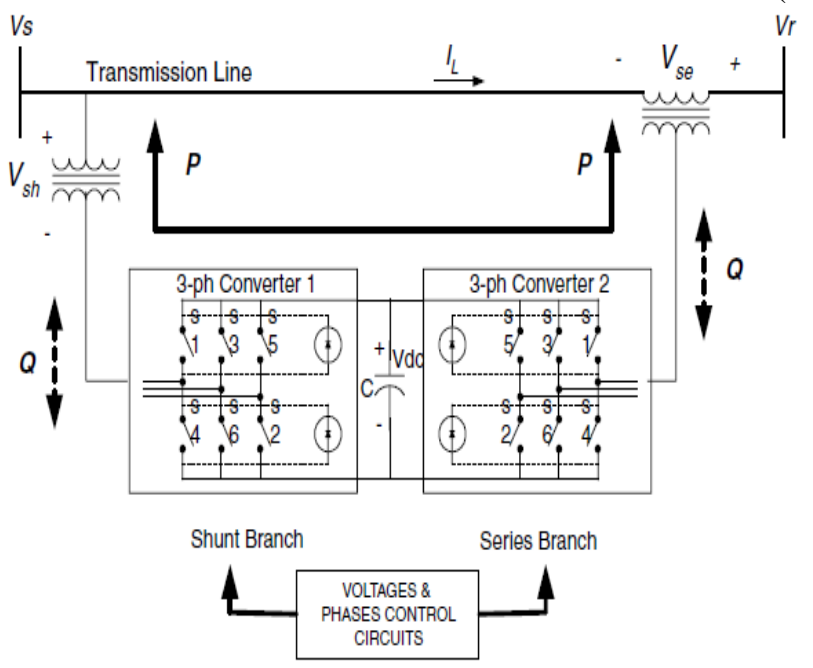

Fig:1 UPFC Principal Diagram

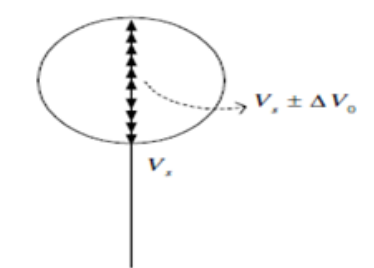

(a). Terminal voltage regulation

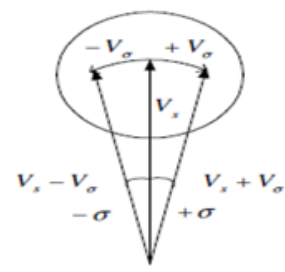

(c). Phase angle shifting

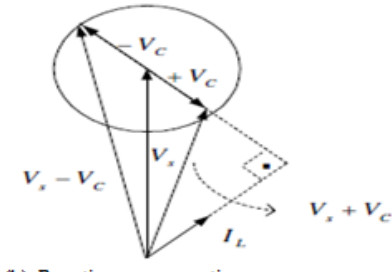

(b). Reactive compensation

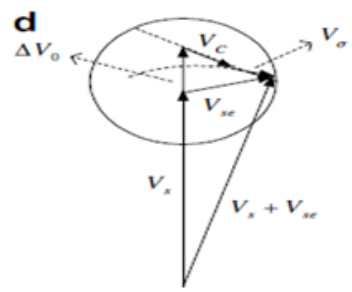

(d). Multi-function control mode
Fig2: UPFC Operating Modes

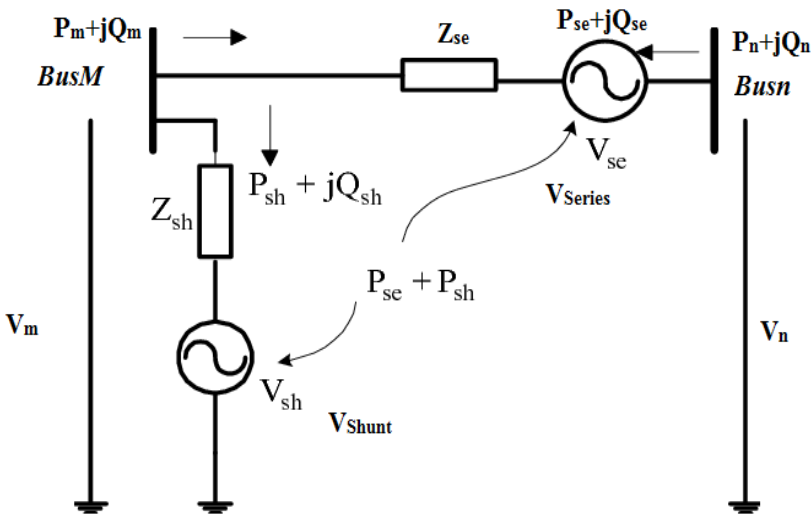

Fig3: Mathematical modeling of UPFC

Converter 1 reactive power supplied [13 ] or consumed is not taken into consideration here, yet its impact will be represented as a different controllable reactive shunt source. Here, 
Reactive power plays a major role in keeping the voltage at bus ' $\mathrm{m}$ ' below the appropriate values.

In perspective on the above clarifications, Qshunt will be made as 0 .

Therefore, UPFC's mathematical model is developed with the expansion of a power injection proportional to Pshunt $+\mathrm{j} 0$ at bus ' $\mathrm{m}$ ' and ' $\mathrm{n}$ 'from the series related voltage source model as shown in fig.3. UPFC's power-injection model is shown in Fig. 4

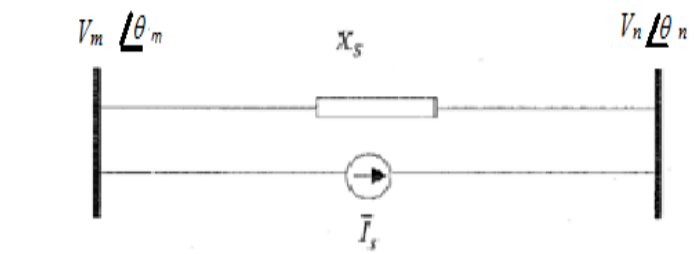

$$
\begin{aligned}
& P_{\text {iupfc }}=r b_{x} V_{s}^{2} \sin \gamma-r b_{2} V_{i} V_{j} \sin (\theta i-\theta j+\gamma) \quad Q_{i u p f c}=-r b_{s} V_{i}^{2} \cos \gamma \\
& P_{j u p f c}=r b_{x} V_{i} V_{j} \sin (\theta i-\theta j+\gamma) \quad Q_{j u p f c}^{\prime}=r b_{s} V_{i} V_{j} \cos (\theta i-\theta j+\gamma)
\end{aligned}
$$

Fig4. UPFC Power injection model

At last, UPFC's mathematical model can be built by joining power injections of series and shunt at both bus ' $m$ ' and bus ' $n$ ' as shown in Fig. 4.

\section{OVERVIEW OF FIREFLY OPTIMIZATION}

Xin-She Yang initially developed the Firefly Algorithm (FA) at the University of Cambridge in late 2007 and 2008. [15] Firefly algorithm caught a lot of attention and applied to many applications. Firefly algorithm is a metaheuristic swarm-based, optimization algorithm inspired by nature.[15] The algorithm resembles firefly's flashing behavior.[16] FA is much like different optimization algorithms using intelligence of swarms like PSO. However, this algorithm is observed to have advanced overall performance in lots of cases [14]. It follows three rules.

1. All fireflies are unisex, and one firefly can be interested in the opposite fireflies regardless of sex.

2. A firefly's attractiveness is related to its brightness, therefore every firefly's movements towards brighter one. More brightness means less away from two fireflies. In any case if two fireflies are having same brightness at that point they move arbitrarily.

3. Fireflies brightness is associated by the fitness function, for maximization problem, fitness is proportional to firefly brightness. For a minimization problem, fitness function is reciprocal to the firefly brightness.

The intensity of light also agrees the inverse square law as in Eq. (15)

$I(r)=\frac{I_{s}}{r^{2}}$

Where intensity at the source is given by $\mathrm{I}_{\mathrm{s}}$, and $\mathrm{I}(\mathrm{r})$ is the intensity of light at a ' $r$ '. The light intensity I varies with the distance $r$ for a given medium with given absorption coefficient ' $y$ ' and is given in Eq. (16).

$\mathrm{I}=\mathrm{I}_{0} \exp (-\gamma \mathrm{r})$ where $I_{0}$ is the intensity of original light, [5] and ' $\mathrm{r}$ ' is the distance between the fireflies. Since a firefly's attractiveness is proportional to the light intensity seen by neighboring fire flies; the firefly's attractiveness $\beta$ is given as

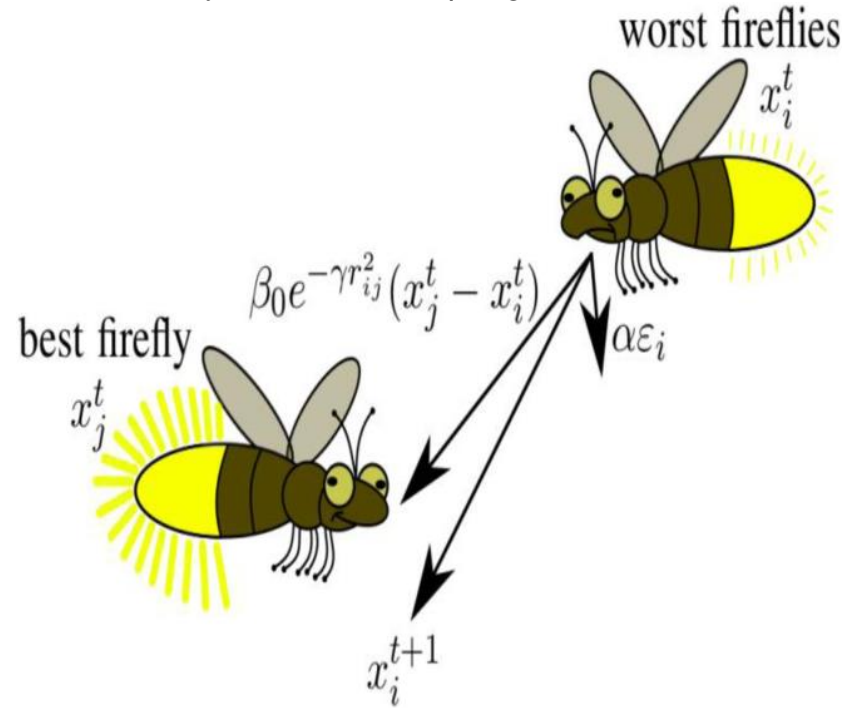

Fig 5: The FA's fundamental mechanism.

$\beta=\beta_{0} \exp \left(-\gamma \mathrm{r}^{\mathrm{m}}\right) \quad(\mathrm{m} \geq 1)$

where the attractiveness at $r=0$ is given by $\beta_{0}$. For two fireflies ' $I$ ' and ' $j$ ', ' $r$ ' is calculated as

$r_{i j}=\sqrt{\sum_{k=1}^{d}(x i, k-x j, k)^{2}}=\left\|\mathrm{x}_{\mathrm{i}}-\mathrm{x}_{\mathrm{j}}\right\|$

Eq. (18) is the difference between any two 'I' and 'j' fireflies respectively at 'xi' and 'xj'.[16] The fireflies travel in each generation to nearby fireflies which have more brightness as defined by Eq. (19) As for in each generation the fireflies move to nearby fireflies

$\mathrm{x}_{\mathrm{i}}=\mathrm{x}_{\mathrm{i}}+\beta \exp \left(-\gamma \mathrm{r}^{2}{ }_{\mathrm{ij}}\right)\left(\mathrm{x}_{\mathrm{i}}-\mathrm{x}_{\mathrm{j}}\right)+\alpha \varepsilon$

Where $\alpha$ randomization parameter is used and is the random number vector taken from the Gaussian distribution. Here step size is controlled by the $\alpha$. The fireflies are ranked at the end of each generation according to their brightness, and the best firefly is found in each generation. For subsequent generations the fireflies are moved, and light intensities of each firefly are modified in relation to the fitness function in each generation. Towards the finish all generations, the firefly with the most elevated brightness for example, the best fitness value is considered as the best solution to the problem. 


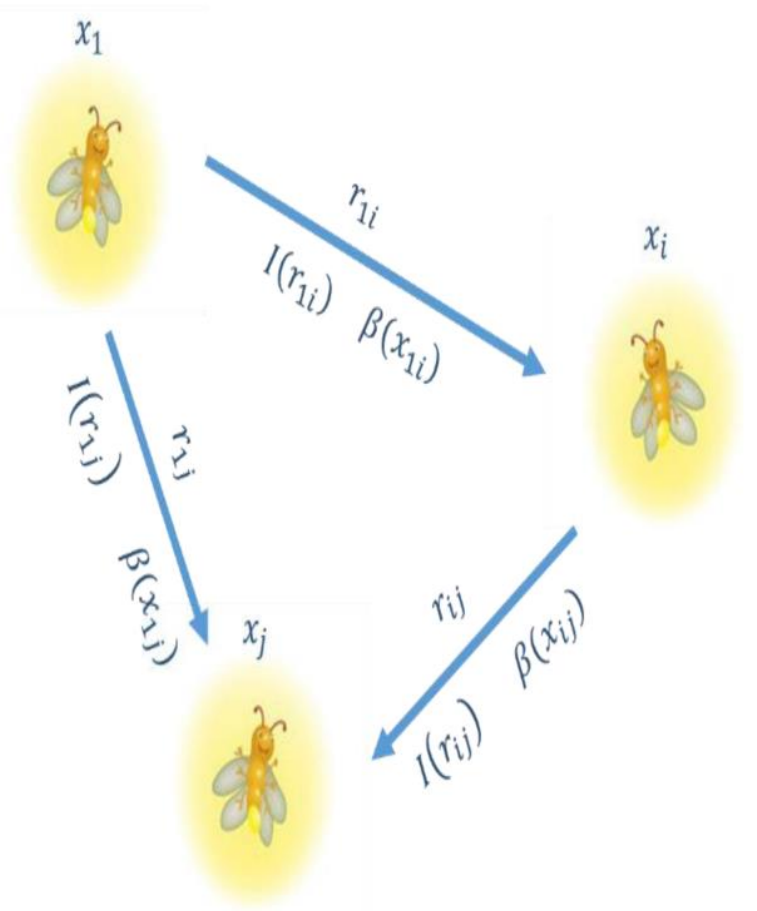

Fig 6: Distance and movement of fireflies

\section{FIREFLY ALGORITHM}

\section{A. Firefly Algorithm}

The procedure involved in the algorithm is as follows

1. Initiate the parameters and constants of firefly. Such as $\alpha, \beta, \gamma, \delta$, maximum number of iterations, and number of fireflies.

2. Iteration counter $I=0$. Initially,

3. Increase counter $\mathrm{I}=\mathrm{I}+1$ for iteration.

4. In each iteration, determine the fitness of the fireflies using the Eq. (1) and relate each firefly's light intensity to the same.

5. Arrange the fireflies dependent on their light intensities and notice the most effective firefly in every iteration.

6. Depending on the gap between fireflies, Vary the perception of all possible fireflies by light intensity.

7. Separate the fireflies dependent on fascination which relies upon their light intensities and furthermore the control parameters.

8. Check the termination process. If it is satisfied go to step IX or else go to step III

9. Display the fireflies with most outstanding light intensity.

\section{B. Firefly algorithm Flow chart}

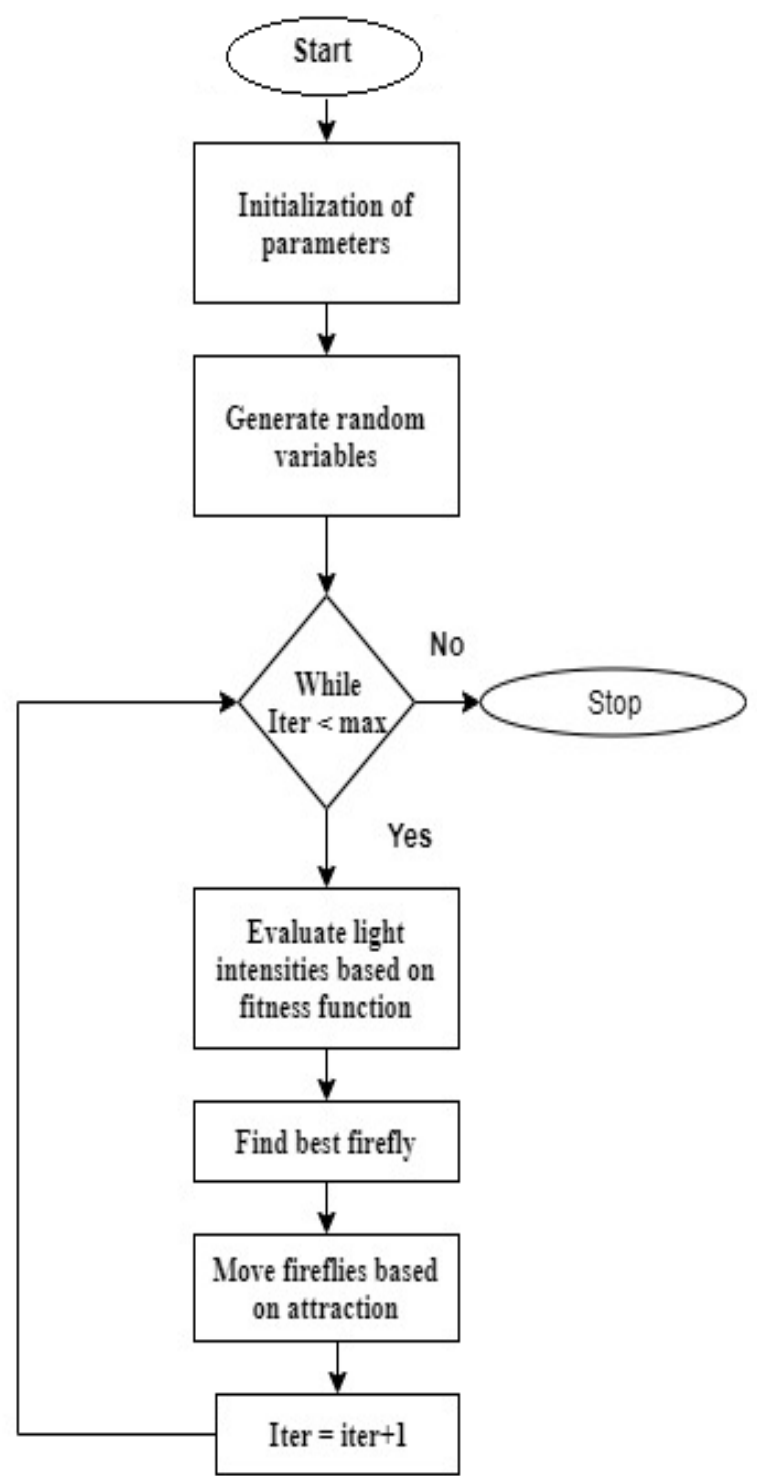

\section{RESULTS AND DISCUSSION}

The sufficiency of the planned firefly algorithm is examined on IEEE 14 bus system. IEEE 14[20] bus system includes five generator buses 1,2,3and 6, nine load buses 4, 5 , $7,9,10,11,12,13$ and14, and twenty transmission lines with three Transformers. The load from normal load was raised by 125 per cent, 150 per cent, and 200 per cent for the IEEE 14 bus test system. For increased load on the network, the L-index raises real power losses and voltage deviation at load buses as well. Nevertheless, L-Index is used to discover the system's heavy loss buses to identify the optimum location for the UPFC. When the system load rises, buses 9 and 14 have high L-Index and so these buses are the optimum places to install the UPFC.

The Firefly algorithm is utilized to determine the optimal UPFC size for multi-objective achievement. And finally, the UPFC devices are positioned with appropriate sizes at buses 9 and 14 and the related results are shown in tables such as real power loss with various loading conditions. 
Table I. Ieee 14 Bus Testsystems Result

\begin{tabular}{|l|l|l|l|}
\hline $\begin{array}{l}\text { Percentage } \\
\text { of Loading }\end{array}$ & $\begin{array}{l}\text { Losses } \\
\text { without } \\
\text { UPFC }\end{array}$ & $\begin{array}{l}\text { Optimal } \\
\text { location of } \\
\text { UPFC }\end{array}$ & $\begin{array}{l}\text { Losses with } \\
\text { UPFC } \\
\text { (MW) }\end{array}$ \\
\hline $100 \%$ & 13.57 & $\begin{array}{l}4-9 \\
9-14\end{array}$ & 13.3796 \\
\hline $125 \%$ & 23.1 & $\begin{array}{l}4-9 \\
9-14\end{array}$ & 22.269 \\
\hline $150 \%$ & 36.028 & $\begin{array}{l}4-9 \\
9-14\end{array}$ & 34.6276 \\
\hline $200 \%$ & 71.7343 & $\begin{array}{l}4-9 \\
9-14\end{array}$ & 70.0624 \\
\hline & & \multicolumn{2}{|l}{} \\
\hline
\end{tabular}

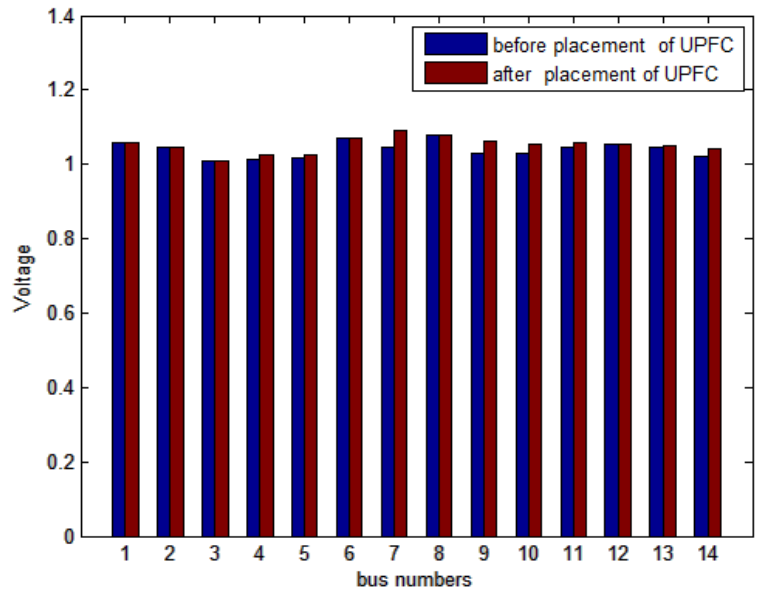

Fig 7: Voltage profile for $100 \%$ of normal loading before and after UPFC placement.

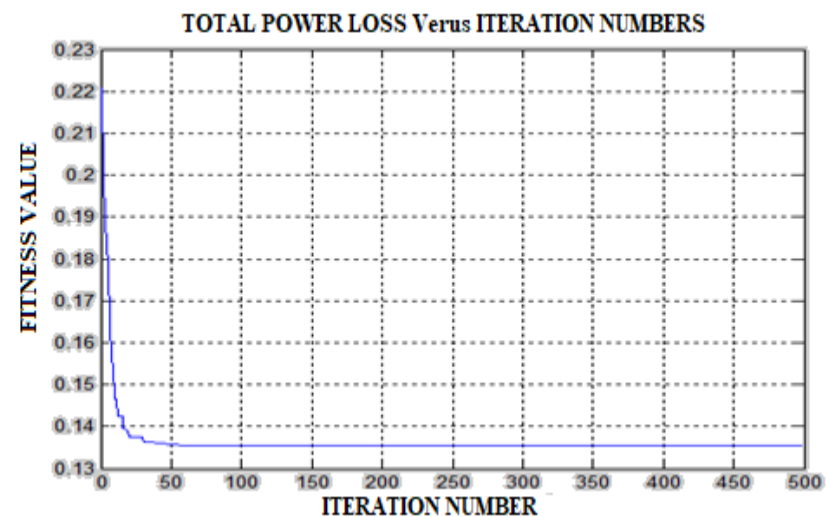

Fig 8: IEEE14 Bus system Convergence characteristics at $100 \%$ of loading.

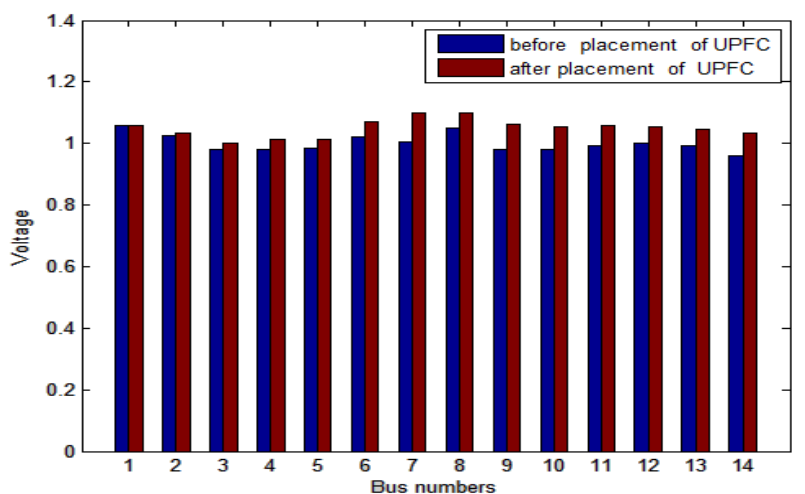

Fig 9: Voltage profile for $125 \%$ of normal loading before and after UPFC placement.

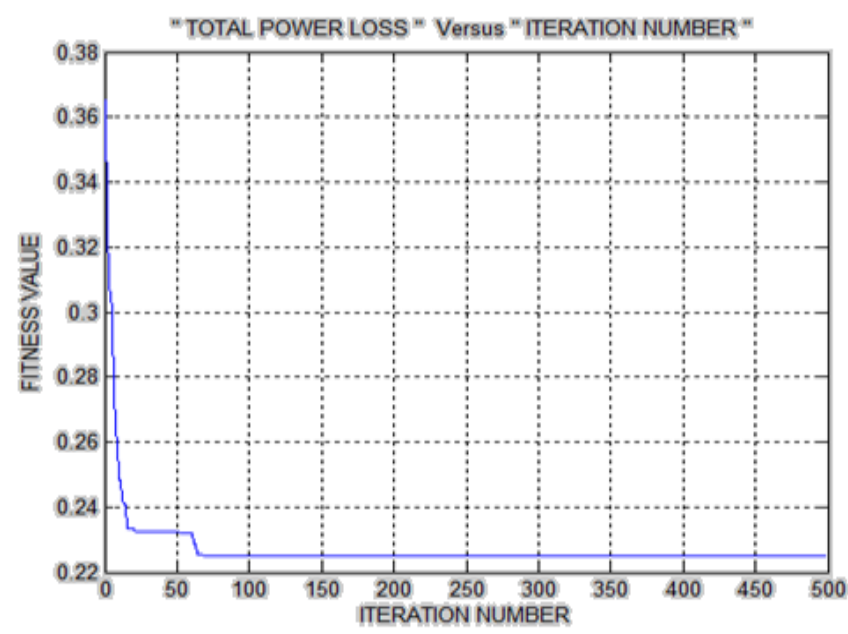

Fig 10: IEEE14 Bus system Convergence characteristics at $125 \%$ of loading.

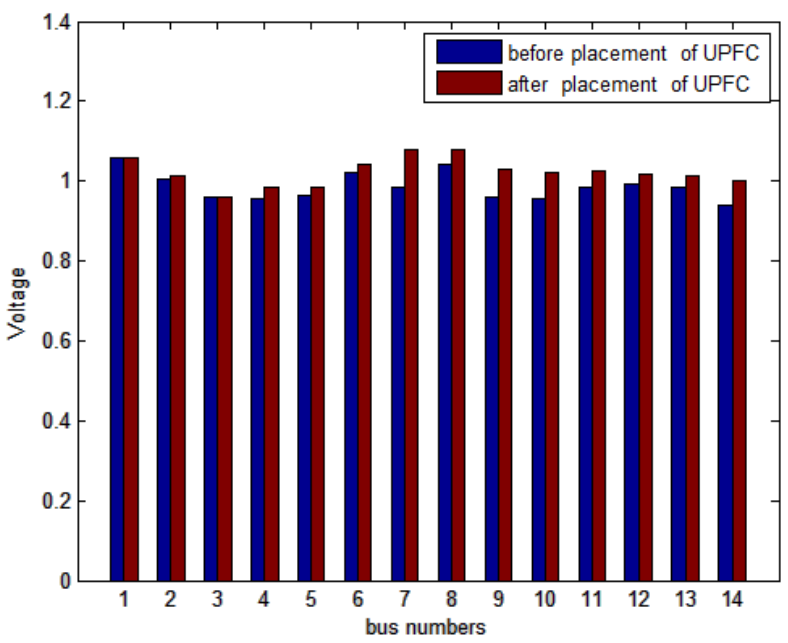

Fig 11: Voltage profile for $150 \%$ of normal loading before and after UPFC placement.

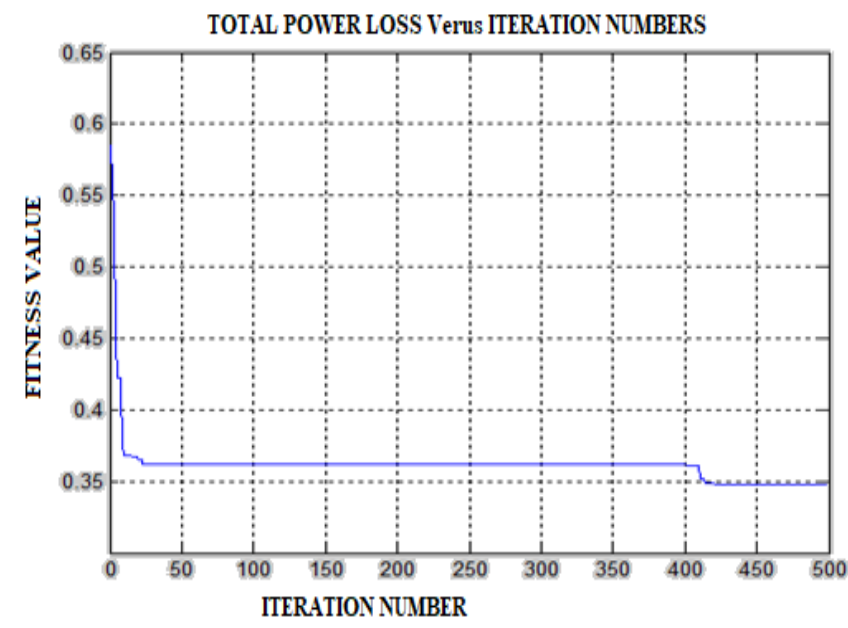

Fig 12: IEEE14 Bus system Convergence characteristics at $150 \%$ of loading.

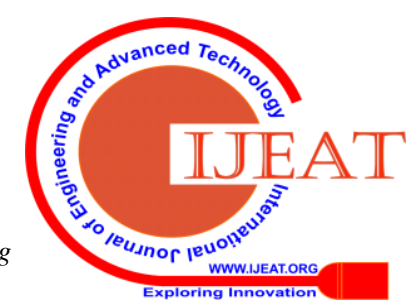




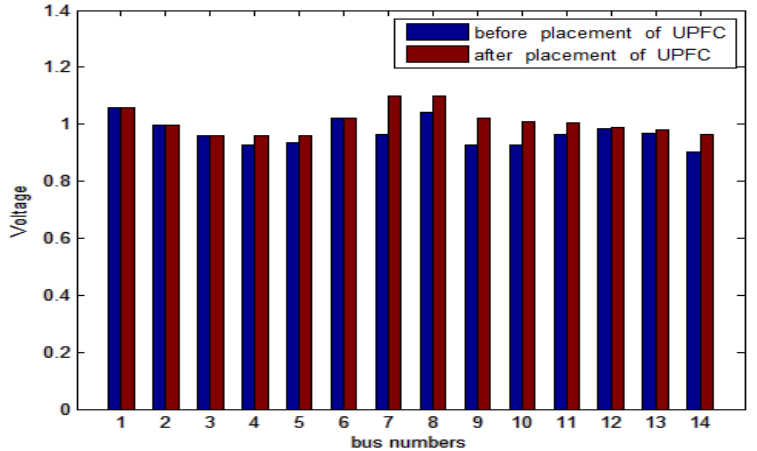

Fig 13: Voltage profile for $200 \%$ of normal loading before and after UPFC placement.

TOTAL POWER LOSS VerUS ITERATION NUMBERS

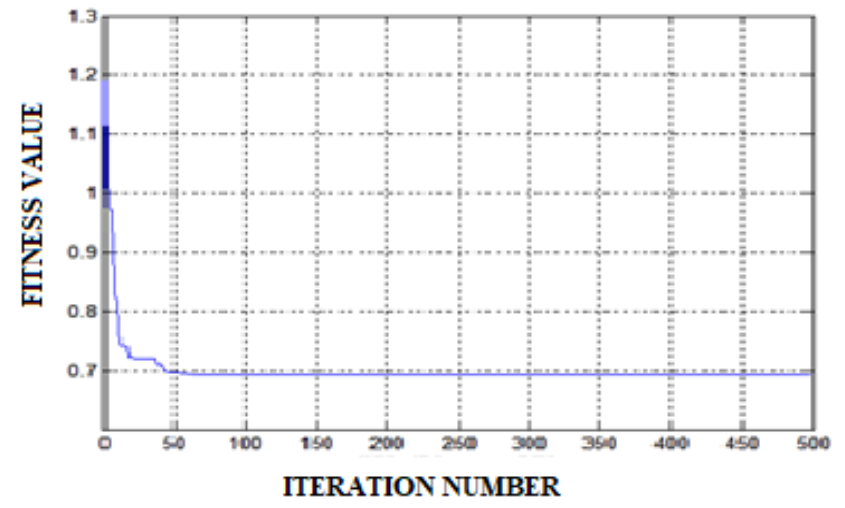

Fig 14: IEEE14 Bus system Convergence characteristics at $200 \%$ of loading.

\section{CONCLUSION}

This research provides two new methods to identifying optimal UPFC positions and sizes for the minimization of Transmission line real power losses. One is the L-index technique to locate the most suitable UPFC positions and the second is the FF algorithm to locate the most satisfying UPFC sizes. The subsequent conclusions shall be drawn on the basis of the simulation results.

[1] By installing UPFC in every possible location, the $g$ ross real power loss of the network has been reduced and the bus voltages are substantially improved.

[2] The suggested L-index method has been able to find the optimal positions of UPFC.

[3] For optimal UPFC sizes the suggested FF algorithm effectively finds maximum power loss reduction.

\section{REFERENCES}

1. Thukaram D, Parthasarathy K, Khincha HP, Udupa Narendranath, Bansila

Voltage stability improvement: case studies in indian power networks. Elect Power Sys Res 1998; 44:35-44.

2. Yesuratnam G, Thukaram D. Congestion management in open access based on relative electrical distance using voltage stability criteria. Electr Power Syste Res 2006; 77:1608-18.

3. Noroozian M, Angquist L, Ghandhari M, Anderson G. Use of UPFC for optimal power flow controller. IEEE Trans Power Deliv 1997:12(4):1629-34.

4. Nagendra P, Halder Sunita, Paul S, Datta T. A novel approach for global

5. Voltage stability assessment of a power system incorporating static var compensator. Eur Trans Electr Power 2012;22(7):1016-26.

6. Gyugyi L. "A unified power flow control concept for flexible AC transmission syst." IEE Proc Part C 1992;139(3):323-31.
7. N.G. Hingorani, L. Gyugyi, and Understanding FACTS: Concepts and Technology of Flexible AC Transmission Systems, New York, IEEE Press, 2000.0

8. Nabavi-Niaki A, Iravani MR. "Steady-state and dynamic models of unified power flow controller (UPFC) for power system studies." IEEE Tran Power Syst 1996; 11(4):1937-43.

9. Glanzman G, Anderson G. Coordinated control of FACTS based on optimal power flow. In: Proceedings, 37th annual North American power symp, Ames, IA, 23-25 October; 2005.

10. Lashkar Ara A, Kazemi A, Gahramani S, Behshad M. Optimal reactive power flow using multi-objective mathematical programming. Sci Iranica Tran D: Comput Sci Eng Electr Eng 2012; 19(6):1829-36.

11. Singh SN, Erlich I. "Locating unified power flow controller for enhancing power system loadability." In: International conference on future power system. Amsterdam, Netherlands; Nov. 2005, p. 162-66.

12. P.Kessel, H.Glavitsch "Estimating the Voltage Stability of a Power System" IEEE, Trans on Power Delivery, Vol.PWRD-1, N3, July 1986

13. Yang XS. Firefly algorithm: stochastic test functions and design a optimization. Int J Bio-Inspired Comput 2010;2(2):78-84.

14. M. Noroozian, L. Angquist, M. Ghandhari and G. Anderson "Use of UPFC for optimal power flow control" in IEEE Trans on Power Delivery, Vol. 12, No. 4, October 1997

15. Huang G.M. and Nair N.K.C. (2001) "Detection Of Dynamic Voltage Collapse," Power System Engineering Research Centre, www.pserc.wise.edu/ecow/get/publication/2002public/dynamic_sum mer.pdf.

16. Xin-She Yang," Firefly Algorithms for Multimodal Optimization", Xiv: 1003.1466v1 [math.OC] 7 Mar 2010.

17. Yang X-S. Nature-inspired metaheuristic algorithms. Luniver Press; UK, 2010.

18. Yang XS. Firefly algorithm for multimodal optimization. SAGA 20, vol. 5792; 2009. p. 169-78.

19. http://www.ee.washington.edu/research/pstca/.

\section{AUTHORS PROFILE}

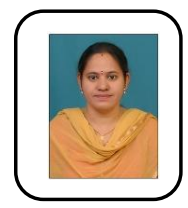

N. Kalpana, has been awarded B.Tech. J.N.T.U., Hyderabad, India, degree in Electrical and Electronic Engineering in 2004. She got M.Tech. Degree in 2009 in the field of electrical power engineering from JNTU College of Engineering, Hyderabad, India. she is pursuing her Ph.D. from Acharya Nagarjuna University,Guntoor, And works as Assistant Professor in the Electrical and Electronic Engineering Department, MECS, Hyderabad. Her areas of interest include stability and regulation of the power system, stability of voltage, FACTS systems, and evolutionary algorithms. optimization techniques

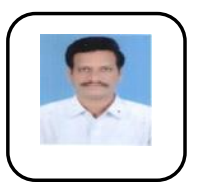

Dr. Venu Gopala Rao M., FIE, Senior Member IEEE at present is Professor \& Head, department of E.E.E., PVPSIT, Kanuru, Andhra Pradesh, India. He graduated from Gulbarga University in 1996 with a B.E. in Electrical \& Electronics Engineering, M.E.(E.P.E) from M S University, Baroda, India in 1999, M.Tech. (Computer Science) from JNT University, India in 2004 and Doctorial Degree in E.E.E. from JNT University, Hyderabad, India in 2009. He published more than 35 papers in various National, International conferences and Journals. His research interests accumulate in the area of Power Quality, Distribution System, High Voltage Engineering, Condition Monitoring of Electrical Machines and Signal Processing. 